\title{
Intento oficial para enfrentar la delincuencia
}

Como parte del paquete de ofertas del presidente Francisco Flores en el marco de su política de "alianzas", a principios de octubre anunció con gran publicidad -característica muy suya cuando de seguridad pública se trata- el "Proyecto de prevención social de (sic) delincuencia". Este hecho se produce luego de los resultados que arrojó la evaluación de la gente sobre su gestión gubernamental, transcurridos los primeros cien días de la misma y faltando cinco meses para que el pueblo salvadoreño —en capacidad y con ánimo de participar- elija una nueva Asamblea Legislativa junto a 262 concejos municipales. Cabe señalar que, con el paso de los años y desde que en El Salvador se acabó la guerra, el Instituto de Derechos Humanos de la UCA ha asumido la situación de violencia e inseguridad que afecta a casi todas las personas, como uno de los aspectos prioritarios que reclaman su atención; de ahí que, en esta ocasión, nos sintamos en la obligación de expresar alguna opinión acerca del citado proyecto.

De entrada, se debe señalar que la responsabilidad de su realización práctica recaerá en el Consejo Nacional de Seguridad Pública (CNSP); éste nació el 8 de enero de 1996 -mediante decreto ejecutivo- "como un ente de carácter consultivo" y desde entonces hasta el 1 de junio de 1999 lo encabezó el ahora ex ministro de Seguridad Pública, Hugo Barrera, contando con la participación de cuatro "personalidades de notoria capacidad e integridad en la vida nacional": Salvador Samayoa, David Escobar Galindo, Luis Cardenal y Mario Luis Velasco. Con la administración Flores algunas cosas cambiaron a partir de septiembre del año en curso, tanto en lo que toca a sus integrantes como en lo que corresponde a su mandato.
Salió Bartera, pues con sobrada razón no fue ratificado en el cargo que ocupó en el gabinete de Armando Calderón Sol; su lugar lo ocupó Samayoa con una especie de "rango ministerial" autoasignado, según confesión de parte en una entrevista reciente. Entró el nuevo ministro del ramo, Francisco Bertrand Galindo, cuyo padre fue el principal asesor de Barrera mientras éste administró la cartera. Cardenal decidió abandonar su compromiso con la seguridad pública del país, mientras intenta intensamente asumir la dirección de la comuna capitalina como representante del partido Alianza Republicana Nacionalista (ARENA); tal vez sea temporal su ausencia, pues nos imaginamos que -de no ganarle al actual alcalde de San Salvador en las elecciones del próximo marzo- no tardará mucho en regresar al Consejo.

No le renovaron el nombramiento a Velasco e ingresó Alexandra Hill; continúa Escobar Galindo, quien entre sus múltiples actividades figuró en el comité asesor del recién finalizado "Programa de Reconstrucción Social" del gobierno canadiense, espacio donde lastimosamente —quizás por falta de tiempo- no se pudo contar con su experiencia y aporte en tan importante materia para el despegue de un verdadero Estado de Derecho, como es la seguridad de las personas y sus bienes; experiencia que se supone debe tener y aporte que también se presume puede brindar, porque de otra manera no tendría mucho que hacer en el Consejo.

Determinar la "notoria capacidad" de la gente que lo integra queda a criterio del presidente de la República, aunque no son muy conocidos los elementos que utiliza para ello. Por qué entran y salen del mismo es, pues, un misterio; un leve y único 
indicio que encontramos sobre eso es lo escrito por Samayoa'. El entonces miembro de base y ahora máxima autoridad del ente escribió en esa ocasión, entre otras cosas, lo siguiente: "Desde un punto de vista puramente político, la designación de los miembros del Consejo constituye una innovadora y sana práctica de gobierno. Los cinco integrantes del Consejo -incluyendo al Ministro- son profesionales o empresarios que no pertenecen al partido oficial ni representan posiciones o intereses de otras fuerzas políticas". Y añadió: "Una designación de este tipo, en un área tan prioritaria y con implicaciones políticas tan sensibles, es una práctica poco usual en nuestro medio y genera de entrada algo de confianza, credibilidad y expectativa en amplios sectores sociales".

Honestamente, lo que dice Samayoa que el Consejo generó entre la población -confianza, credibilidad y expectativas- no lo logramos percibir desde nuestro espacio, quizás porque en estos ámbitos no tenemos la información necesaria y suficiente, o porque no estamos en perfecta sintonía con ese especial discurso oficial que se instaló en el país después del fin de la guerra: retórico, hábil vendedor de imágenes, diplomático en exceso y duro con sus críticos. Sin embargo, en otros sitios sí despertó algo; por ejemplo, el secretario general de las Naciones Unidas se refirió - en noviembre de 1996- a "las grandes expectativas suscitadas por la creación del Consejo Nacional de Seguridad Pública por el presidente Calderón Sol"2 .

Y agregó, quizás con exceso de optimismo, lo que sigue: "Si bien ha habido un retraso en la definición de sus mandatos y objetivos, me satisface señalar que el presidente de la República ha expresado repetidamente su apoyo a las propuestas presentadas por ese Consejo. Esta circunstancia es particularmente relevante, puesto que las posiciones definidas por el Consejo corresponden claramente a la doctrina de seguridad pública establecida por los acuerdos de paz. A este respecto, no me cabe duda de que el Consejo, siguiendo las instrucciones precisas del presidente, procederá a reforzar las instituciones del sector de la seguridad pública mediante una amplia reestructuración que confiera una mayor coherencia a las políticas gubernamentales. Asimismo, estoy en espera de las recomendaciones concretas que formule el Consejo dirigidas a resolver los problemas más sensibles que se siguen verificando en el sector de la seguridad pública"3.

Desde su origen hasta hace unos meses, según afirmaciones propias, el CNSP concentró sus esfuerzos en asesorar al primer mandatario en la formulación de políticas - generales y específicas - sobre seguridad pública; no obstante, sus recomendaciones no se materializaron según lo dicho por Samayoa en una entrevista y - sobre todo- por lo que ha seguido padeciendo la población: violencia, inseguridad y temor. Para desencanto de la ONU y de quienes dice confiaron, creyeron y esperaron algo del Consejo, su actual presidente - tras tomar posición de ese cargo- declaró que el presidente Flores "dice que sí quiere hacer las cosas. El anterior, por las razones que sea, no las quiso o no las pudo hacer"4. Al pedirle su opinión sobre el incumplimiento de las recomendaciones, dijo que era "muy simple: el presidente anterior nombró al Consejo porque tenía presión de las Naciones Unidas, no porque tuviera la convicción de que era muy importante tener a un grupo de personas de la sociedad civil para que le ayudaran a formular e implementar la política de seguridad pública del pais"s.

Al momento de escribir estas líneas, no sabemos si ya modificaron su mandato para ampliarlo; el caso es que ahora el Consejo también impulsará la ejecución del proyecto preventivo que ahora nos ocupa, tal como aparece en la introducción del documento mediante el cual se presenta. Además, en ese texto se dice que de hecho el CNSP "pretende hacer converger $\mathrm{y}$ articular todas las iniciativas,

1. La Prensa Gráfica, 11 de enero de 1999, p. 10-A.

2. Informe del secretario general, oficina de las Naciones Unidas para la Verificación en El Salvador. "La situación en Centroamérica: Procedimientos para establecer la paz firme y duradera, y progresos para la configuración de una región de paz, libertad, democracia y desarrollo", Quincuagésimo primer período de sesiones, Tema 40 del programa, Asamblea General, A/51/693, 25 de noviembre de 1996, numeral 4.

3. Ibíd.

4. La Prensa Gráfica, viernes 27 de agosto de 1999, pp. 26 y 27.

5. Ibíd. 
planteamientos, criterios de acción, prioridades, etc., que diversas y numerosas instituciones, organismos, sectores particulares, etc., han desarrollado con el objetivo de dar una respuesta preventiva, de carácter social, a la violencia delictiva que atraviesa nuestro país"6.

Aprobada o no esa nueva misión, el caso es que se impulsará este proyecto que es parte de lo que el gobierno de Flores ha denominado "el nuevo modelo de seguridad". En teoría, los componentes de dicho "modelo" son los siguientes: fortalecimiento de la prevención social de la delincuencia, fortalecimiento de la participación ciudadana en la prevención de la conducta delictiva, fortalecimiento de los mecanismos de apoyo a la Fiscalía General de la República en la conducción de la investigación del delito, apoyo a la Corte Suprema de Justicia en el logro de la eficacia judicial, desarrollo de esquemas para la efectiva rehabilitación social del delincuente, cooperación internacional para la seguridad pública y aseguramiento de la eficacia policial.

Ese es el marco en el cual debe analizarse el llamado "Proyecto de prevención social de delincuencia": como parte de algo que pretende ser un plan integral impulsado por la actual administración del Órgano Ejecutivo para garantizar la seguridad pública. En principio, nadie en su sano juicio está en contra de este tipo de iniciativas pues estamos hablando de lo que a estas alturas es junto con el tema económico y social- la mayor preocupación de la sociedad salvadoreña; ni nosotros ni nadie debe cuestionar las acciones que realmente apuntan a la superación de una situación insoportable. En el caso que ahora desarrollamos, consideramos importante plantear algunas preocupaciones que brotan de inmediato al conocer la propuesta gubemamental.

La primera tiene que ver con una interrogante fundamental: ¿de dónde surge el "nuevo modelo"? Sabemos que el equipo de trabajo del anterior Consejo Nacional de Seguridad Pública organizó e impulsó —en 1998 - un proceso de consulta para elaborar una propuesta sobre la materia, destinada a convertirse en un insumo básico para el futuro gobierno sin importar su color político. En el marco de una situación cada vez más crítica para la pobla- ción, este equipo - según lo manifestado en una reunión realizada a finales de julio de ese año- pretendía construir una visión integral e integrada de mediano y largo plazo, que trascendiera el período de una administración del Órgano Ejecutivo; entonces se dijo que habían trabajado con cerca de sesenta instituciones nacionales $e$ internacionales, con las que se analizaron alrededor de diez temas relacionados con la materia.

Pero también sabemos que después de haber sido ungido como el candidato a la presidencia de la República por ARENA, Francisco Flores integró diversos grupos de trabajo y uno de ellos se encargó de formular lo que en la campaña electoral se conoció como la "alianza por la seguridad"; no se conoce quiénes integraron ese "grupo especializado" ni el enfoque y la metodología que se utilizaron para la concreción de esta iniciativa.

La inversión para la elaboración del "Plan de Nación" fue considerable, tanto en lo económico como en recursos humanos y tiempo. Así como en el caso del Consejo Nacional de Seguridad Pública al momento de su creación, esta iniciativa despertó expectativas; sin embargo, entre sus diecinueve mesas de trabajo no se incluyó desde ninguna perspectiva el tema que ahora abordamos. Pero no importa, pues de todas maneras - fuera del reciente anuncio del presidente Flores, tras más de cien días de andar por ahí sin rumbo claro- parece que el famoso "Plan de Nación" no ha sido tomado en cuenta de forma seria.

En un cuadro comparativo incluido en el reciente proyecto del Consejo se establece que su primer documento, denominado "elementos básicos para una estrategia de seguridad pública", ya señalaba los siete componentes que ahora aparecen dentro del "nuevo modelo". ¿Será esa la base o el "nuevo modelo" es producto de las mesas de trabajo organizadas por el partido ARENA, en el marco de la campaña electoral de quien ahora se encuentra instalado en Casa Presidencial? ¿Se consideró en serio el resultado de la consulta realizada por el equipo del Consejo Nacional que arrancó en 1998? De nada nos sirve quedarnos instalados en las especulaciones sobre estos aspectos; mejor concentremos nuestra atención en el proyecto específico que ahora ofrece el CNSP.

6. Consejo Nacional de Seguridad Pública, "Proyecto de Prevención Social de Delincuencia", San Salvador, 5 de octubre de 1999, mimeo, p. 1. 
Es obvio que para prevenir desde la sociedad el fenómeno delincuencial, se debió contar con la participación de las expresiones de ésta que de alguna manera podían aportar constructivamente a la elaboración y puesta en marcha de un plan de tal envergadura; hablamos de empresa privada, iglesias, universidades, grupos cívicos y otras instituciones. De lo contrario, de nuevo nos encontraríamos ante el peligro real de estar ante otra operación de maquillaje con evidentes fines electoreros. Ante la falta de acciones estatales en el ámbito preventivo, existen experiencias concretas realizadas con destacado protagonismo desde la sociedad que sin duda era conveniente considerarlas para la ubicación de las causas de la delincuencia y el diseño de actividades preventivas.

Recordemos que incluso en el documento presentado por el Consejo para lanzar su proyecto, se hace un mea culpa explícito que apunta hacia la ausencia de una política pública efectiva por parte de la anterior gestión del Órgano Ejecutivo en el ámbito de la prevención. "El cambio - se diceha comenzado a producirse desde el inicio de la nueva administración". Por eso mismo, era necesario detenerse en lo que las llamadas "fuerzas vivas" del país habían avanzado en este camino y buscar concertar con dichos entes particulares los ejes centrales para la elaboración del proyecto; esto habría dado un mejor soporte social al plan ahora presentado por las autoridades.

Pero aunque asumamos que en algo influyó aquella consulta a la que ya nos referimos, realizada por el Consejo en 1998, se debe hacer otro señalamiento crítico. No parece existir ninguna senal, hasta la fecha, en lo relativo a la forma cómo la sociedad va a verificar su puesta en práctica. Sólo de una manera difusa se hace referencia, dentro del plan, a diversos "estudios" que sirvieron de base para el proyecto y se menciona que el Consejo también buscará "complementar los seis componentes de su proyecto con iniciativas de cualquier institución que oriente su trabajo en una dirección coincidente".

Que no era ninguna "varita mágica" dijo el coordinador del Consejo Nacional de Seguridad Pública, al referirse con prudente entusiasmo al proyecto durante el acto de su presentación. No hay duda de eso, pero tampoco de que es novedoso; ¿cuándo en El Salvador se había ofrecido algo así? Lo que no resulta ser nada nuevo en nuestro

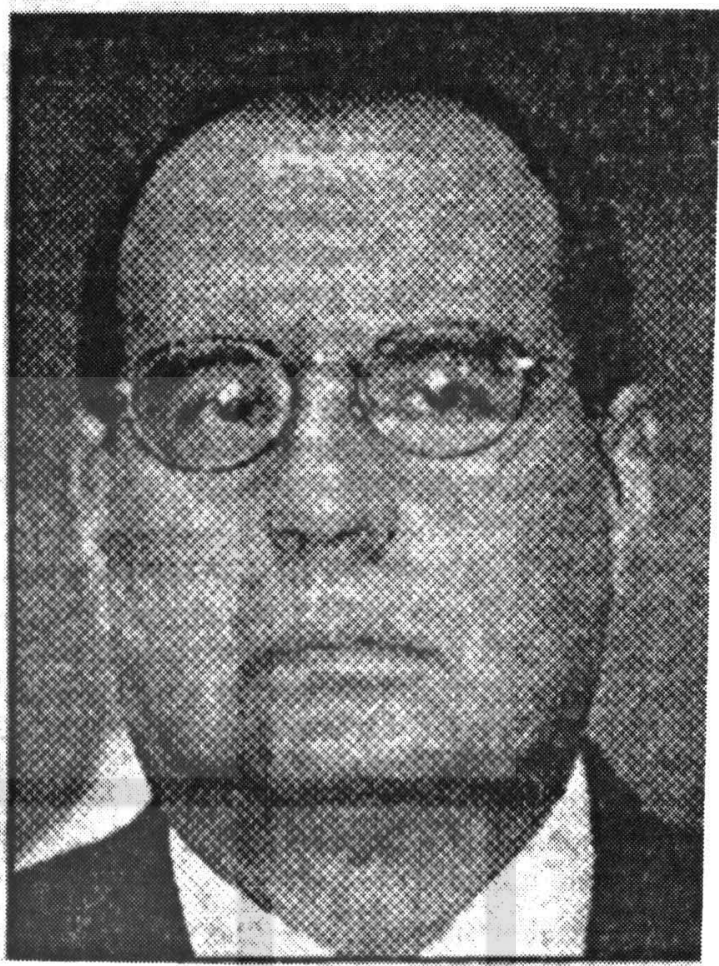

país son las tantas promesas de solución por vías inadecuadas y de consecuencias frustrantes en el campo de la seguridad pública; hablamos de "juntas de vecinos", planes "Caminante" y "Guardián", "ley de emergencia" y pena de muerte, entre otras. Conociendo esas experiencias, cabe preguntarse si esta nueva iniciativa será la forma óptima de prevenir la delincuencia.

Según lo expuesto ante la Nación, este programa encuentra su razón de ser en el hecho de que la "prevención social es el fundamento de la seguridad pública". Para precisar las cosas es válido recordar que cuando el presidente Flores presentó a la opinión pública su "nuevo modelo", tres días después de haberse posesionado de su actual cargo, incluyó la prevención social entre los componentes del plan estratégico. ¿Qué acciones propone este gobierno para impulsarla? Según lo dicho en esa oportunidad, son cuatro: prevención policial, eliminar causas, disuasión, y valores-educación.

El "Proyecto de prevención social de delincuencia" define su orientación: sólo hacia la juventud; en sus palabras: "es una prevención primaria de la violencia y la delincuencia, centrada en la población juvenil de las ciudades que presentan mayo- 
res factores de riesgo"7. Para tener más claridad, por "prevención primaria" se entiende la que "actúa más sobre el entorno social, para prevenir nuevos casos de violencia o delincuencia"s; entre los factores de riesgo - "el entorno social más proclive a la incubación de conductas delictivas" ${ }^{\text {ng }}$ - se incluyen los siguientes: territorio de un predominio urbano; población mayoritariamente masculina, víctima de violencia o abusos en su infancia, que ha desertado o ha sido excluida del sistema escolar, sin sentido de pertenencia, sin empleo y sin perspectivas de conseguirlo; no hay espacios para la recreación y el deporte; hacinamiento.

En otras palabras: ser un hombre joven que vive en las ciudades de El Salvador, con un pasado de violencia y un presente sin acceso a la educación ni identidad, desempleado y sin oportunidades para trabajar, hacer deporte y recrearse es visto como un potencial delincuente. Desde esa perspectiva, para echar a andar el plan proponen los componentes que presentamos a continuación de manera resumida.

Educación: identificarán "las escuelas más problemáticas y con mayor incidencia negativa en la comunidad", hasta convertirlas en "los mejores centros escolares". Empleo: se piensa "estructurar una oferta especial de empleos en distintas categorías (empleos de vacaciones, aprendices, tiempos completos para egresados)", para "los mejores estudiantes de los institutos y escuelas más problemáticas". Deporte: tratarán de "incorporar masivamente a los jóvenes, en modalidades de escuela y de torneos sociales posibilitando la práctica del deporte en horas nocturnas". Actividad cultural: identificarán proyectos comunitarios, principalmente en teatro y festivales musicales, así como "espectáculos o exposiciones de artistas nacionales o extranjeros que puedan presentarse en las comunidades"; asimismo, pretenden promover "concursos intercolegiales e intermunicipales que incentiven la participación y la excelencia.

A los componentes ya señalados, se deben agregar los siguientes. Organización y liderazgo vecinal: se intenta "fomentar y fortalecer la organización y el liderazgo vecinal, de manera sencilla y práctica, sin vinculaciones orgánicas a redes aje- nas al espacio vital inmediato de cada vecindario". Policía comunitaria: ésta es competencia de la PNC y el Consejo sólo coordinará con su dirección general y sus mandos medios o jefaturas para asegurarse que el accionar de las futuras "patrullas de intervención policial comunitaria" (PIT) no choque con el "Proyecto de prevención social de delincuencia". Visto lo anterior - tanto el "nuevo modelo" de Flores como la propuesta puntual del Consejo Nacional- resulta legítimo que nos surjan ciertas inquietudes. No cabe duda que el proyecto específico además de novedoso es "atractivo" y, como tal, ha logrado despertar algunas expectativas entre una población cansada de tanta violencia, delincuencia e impunidad; sin embargo, se queda corto y corre el peligro de ser otro factor más de frustración y desencanto.

Como ya vimos, en el documento se esbozan diversas causas o "factores de riesgo" de la "delincuencia juvenil"; básicamente los componentes del proyecto están dirigidos a ese tipo de delincuencia. Por lanzar a la discusión un ejemplo, entre otros, de algo que nos genera reservas. Es importante anotar que una de las causas del fenómeno que se mencionan es la carencia de empleo y la imposibilidad de poder obtener uno. Tal afirmación es veraz y cualquiera empezaría a tener optimismo y cierta simpatía con el plan partiendo de ella; pero la forma en que se pretende enfrentar dicha causa no es la adecuada, ya que se plantea - según lo expuesto por las autoridades del Consejo- únicamente ofrecer trabajo a los mejores estudiantes de los "colegios problemáticos" y algunos empleos temporales en períodos de vacaciones para los estudiantes de los citados recintos.

En sí, esa "solución" no es la más feliz para enfrentar el desempleo y es poco lo que puede contribuir a atacarlo como una de las causas que generan delincuencia. Sin duda, desafío tan enorme exige la realización de transformaciones verdaderamente profundas que trascienden a las propuestas del plan. El problema del desempleo tiene mucho que ver con el proyecto de sociedad que se está imponiendo en El Salvador; en lugar de aliviarlo, lo incrementa. Soluciones verdaderas a esa realidad apuntan hacia políticas económicas y sociales

\footnotetext{
7. Ibíd., p. 4

8. Ibid.

9. Ibid.
} 
adecuadas, pensadas en función de las mayorías excluidas, marginadas y pobres.

Según el proyecto, el CNSP propone ofrecer trabajo a algunos estudiantes de los colegios "críticos"; pero, mientras, el gobierno que impulsa esas y otras acciones para prevenir la delincuencia también habla de gravar con el impuesto al valor agregado a los productos básicos y de mantener fijos los salarios de las personas que trabajan en la administración pública; anuncia que no se repondrán las plazas vacantes en el Estado, que no se incrementará el salario mínimo y que se elevarán los costos de la energía eléctrica. Entonces, de qué servirán dos decenas de empleos si millones de habitantes —dentro de ellos un buen porcentaje de jóvenes- se verán afectados por tales políticas.

Para continuar con algunos ejemplos, consideramos que el proyecto también se queda corto en lo relacionado con la llamada "policía comunitaria", cuyo impulso queda en manos de la dirección general del cuerpo. Cabe mencionar que la actual conducción de la PNC sólo ha dado señales interesantes en lo relativo al manejo publicitario de la institución, lo que no basta para levantar una imagen bastante deteriorada de la misma. Este problema no se va a superar sustancialmente con mensajes en los medios, mientras en la realidad la actuación de sus elementos sigue dejando mucho que desear y mientras en la cúpula policial se siguen detectando signos negativos en aspectos tales como la transparencia de sus responsables. De no superar esto, se vuelve más difícil recuperar la confianza de la población y fomentar su participación asociada en esfuerzos de este calibre.

Otro aspecto que genera incógnitas y, a la vez, resulta siendo una inquietud: ¿cómo se va a enfrentar el crimen organizado? ¿cómo se combatirá el narcotráfico, el secuestro, el lavado de dinero, los asesinatos planificados, las millonarias estafas, el robo de vehículos a gran escala, la falsificación o alteración de documentos de identificación o de Iránsito, la corrupción gubernamental? Al respecto, Samayoa afirma: "El crimen organizado es la madre de la criminalidad y requiere de mucha voluntad política e inteligencia policial para combatirlo. El Consejo no se mete en este tema, porque el crimen organizado se combate con represión y acción policial, no con programas de prevención.
Esta es responsabilidad del Órgano Judicial y la Policía"

En parte, estamos de acuerdo con el actual presidente del Consejo; pero consideramos que, situados en la realidad salvadoreña, de muy poco servirán sus esfuerzos si no se enfrenta con seriedad el problema del crimen organizado. Y es que no pensamos que sea serio el planteamiento gubernamental en esta área cuando en la práctica las cosas apuntan hacia otra dirección: la situación de la conducción en la Corte de Cuentas y en la Fiscalia General de la República, son sólo dos ejemplos. Además, en estos casos — cuando se publicita un "golpe"- nunca caen cabecillas de verdad o autores intelectuales. Ello, pese a que son delitos cometidos a diario en nuestro país y que la impunidad que cobija a sus responsables últimos incide en la percepción negativa de El Salvador, donde no se captura a este tipo de delincuentes; así, no hay duda que se incentiva la realización de esos y otros hechos que desarticulan la convivencia social.

Si las interrogantes planteadas en estos campos no son contestadas o ni siquiera tomadas en cuenta por el Consejo Nacional de Seguridad Pública y las autoridades del ramo - como ha ocurrido antes-, difícilmente se podrá creer en la sinceridad de la "nueva política de Seguridad Pública" y de una verdadera prevención de la delincuencia. Obviar de entrada los aspectos señalados y otros o no enfrentarlos con responsabilidad, puede traducirse en la posibilidad cierta de que algunos de esos jóvenes - a pesar que van a ir a los tomeos de fútbol y que van a ver pintada su escuela- sean contratados como sicarios por los "narcos" o para saldar cuentas, o para... Si los "capos" del crimen organizado les ofrecen jugosas recompensas para tales efectos y actúan con sobrada impunidad en el país, no es aventurado ni fantasioso pensar que en sus condiciones actuales - se rindan ante tal "tentación".

Dice un adagio jurídico: "quien puede lo más, puede lo menos". Pero la lógica de las autoridades salvadoreñas en el ramo de la seguridad pública, por lo visto es ajena a este precepto y quiere justificar su razón de ir persiguiendo al ratero y acosando al joven de ciertas características, sin ponerse a meditar sobre el crimen organizado como un

10. La Prensa Gráfica, viernes 27 de agosto de 1999, pp. 26 y 27. 
factor fundamental que determina también a la delincuencia y socava valores. En ese marco, causa asombro que el propio ministro de Seguridad Pública haya declarado - a pocos días de la presentación del proyecto de "prevención social"- que no se iban a investigar a los propietarios de los casinos ni a las actividades de estos negocios, no obstante los graves señalamientos hechos en sendos reportajes periodísticos sobre el tema. No es un simple comentario ni capricho el insistir que debería enfatizarse en la lucha contra el crimen organizado, si de verdad se quiere prevenir la delincuencia generalizada en el país.

Podríamos introducimos en otros temas como la ausencia de indicadores para determinar los avances o retrocesos de la propuesta; el por qué se anuncia con tanta propaganda, antes de tener algunos resultados tangibles sobre todo cuando en la práctica se trata de experimentos concretos - focalizados y con pretensión de aplicarse en otros sitios después- y no de una política nacional. También podríamos atrevernos a señalar nuestras dudas sobre lo que puedan inspirar, a sus destinatarios, algunos integrantes del llamado Comité de Gestión del Proyecto; es más, sería interesante conocer la razón de este cambio en la actuación del Consejo, que en la realidad pasa de ser un ente originariamente asesor -con poco éxito en el acatamiento de sus recomendaciones - a ejecutar un proyecto concreto; ¿por qué, en lugar de consolidar las entidades ya existentes o la creación de otra que trabaje específicamente el tema de la prevención social, se toma esa decisión?

Pero quizás después, con más elementos, podamos profundizar en el análisis de la propuesta global del "nuevo modelo de seguridad pública" y del proyecto específico del Consejo Nacional encabezado por Samayoa. A él le deseamos éxitos en la empresa pues, de alcanzarlos, se estará beneficiando de verdad a la sociedad entera. Eso sí: hablamos de éxitos reales; no de publicidad. Pero también deseamos que, de no caminar la experiencia, se decida a señalarlo con todas sus letras - causas y responsabilidades - antes de que transcurran tres o cinco años, para que no suceda lo mismo que durante la administración Calderón Sol. Aspiramos, como Samayoa, a que todas y todos no enfrentemos la necesidad de buscar el rumbo al norte tras esperar - como dice Juan Luis Guerra- "visa para un sueño" en los jardines de la aristocracia; a que todas y todos vivamos en una país como el "vecindario" que él añora: "era un lugar agradable. En realidad era mucho más que un lugar agradable. Era casi un privilegio: por su clima fresco, por sus pequeñas alturas circundantes y por su abundante vegetación"11.

\section{Instituto de Derechos Humanos de la Universidad Centroamericana "José Simeón Cañas"}

11. Salvador Samayoa, "Mi vecindario", El Diario de Hoy, jueves 28 de octubre de 1999, p. 20. 